\title{
The Position of Industry 4.0 in the Worldwide Logistics Chains
}

\author{
Bibiana Bukova $^{1 *}$, Eva Brumercikova $^{1}$, Lenka Cerna $^{1}$ and Pawel Drozdziel ${ }^{2}$ \\ ${ }^{1}$ University of Zilina, Faculty of Operation and Economics of Transport and Communications, \\ Department of Railway Transpor, Univerzitna 1, 01026 Zilina, Slovak Republic; Email: \\ bibiana.bukova@fpedas.uniza.sk,eva.brumercikova@fpedas.uniza.sk, lenka.cerna@fpedas.uniza.sk \\ ${ }^{2}$ Lublin University of Technology, Nadbystrzycka 38 D, 20 - 618 Lublin, Poland; Email: \\ p.drozdziel@pollub.pl
}

\section{*Corresponding Author: Bibiana Bukova}

\begin{abstract}
Optimisation and stimulation of production, digital business, the fourth industrial revolution - this is how the current global economy is perceived. Continuous development of new information and communication technologies, economic globalisation, integration of financial markets, growing pressure on boosting higher added value, just as well as the ever- increasing differentiation of demand schemes became a challenge for the global economy. The article elaborates on the implementation of Industry 4.0 in the logistics, logistic chains as well as use of the Industry 4.0 in logistics. The article includes a new definition of logistics due to the Industry 4.0, which extends the basic production factors by a new term - ,information“.
\end{abstract}

Keywords: Logistics 4.0, Supply chain 4.0, Smart logistics, Industry 4.0

\section{Introduction}

It has been confirmed that the original production factors, i.e. labour, land and capital have been extended by an additional important factor, namely information. The information are getting to the forefront, other factors have limited sources, especially in the future.

The concept named Industry 4.0 first emerged at the Hannover Fair in 2011. It was presented by a group of German industrial scientists and managers. The main objective of the concept was the effort of the Federal Republic of Germany to ensure global competitiveness of the German economy [1-5].

Industry 4.0 is called "Internet of Things", or possibly "SMART systems".

The SMART Manufacturing Leadership Coalition (SMLC), a non-profit organization in the United States of America comprises professionals in the area of industrial production, services, technology companies, government agencies as well as research laboratories [4,6,7]. 
The SMART systems have already been used for a long time by consumers all over the world. Thanks to cashless payments and introduction of loyalty cards of commercial chains an “information warehouse" has gradually been built up. In 1983 this interconnection with customers was first initiated by the American commercial giant Wallmart. The basic principle is to use the information acquired from customers, which until then stayed forgotten and idle. Based on this information a commercial chain can plan its purchase, stocks, and distribution, optimize assortment as well as offer to customers in its individual stores [7].

The „Internet of Things“ is also presented as a cyber-physical system, which communicates and cooperates between itself and people in real time. That means that each product will be a carrier of an electronic communication subsystem, which will be sending and receiving information around and it will be using them for different purposes [4,7].

\section{Logistics 4.0}

Industry 4.0 changes situation in not only the logistics, but it also brings along new requirements to supply chains and shipping services, though different applications and technologies overlap.

There exist many different types of logistics and there exist many definitions of logistics, nevertheless, what should be the definition of Logistics 4.0? In case we derive from the basic logistics definition, the Logistics 4.0 connects production with consumption using artificial intelligence; it digitizes supply chains. The smart supply chain forms the basis of Logistics 4.0.

The supply chain 4.0 also consists of elements such as smart, automated, not exclusively intracompany transport (e.g. road freight driverless transport), smart automated loading operations (using the RFID technologies), smart "containers", smart - automated storing, again, for example, with the use of the RFID technology. A decisive role is played by industrial information technologies within the frame of the company information systems as well as proper understanding of all the data and information for the supply chain managing $[2,8]$.

It is essential to provide for security of information within the whole system of not only the company logistics, which secures safe exchange of information between its participants and concurrently ensures data sovereignty for the involved data owners.

Industrial data spaces represent just one approach, which is strongly supported by people of Logistics 4.0. Anybody dealing with the future of logistics has already undoubtedly studied the potential of the block-chain technology in the management of a supply chain and autonomous type of logistics.

In spite of the intensified on-going discussions on industry digitization and digitization of logistic and supply chains with internet (enabling the use of multiple logistics together with other 
technologies), digital supply chains and (self) autonomous decisions as well as logistic activities such as self-propelled vehicles, the role of the employees in managing a supply chain has, by far, not yet ended $[2,4]$.

Regardless of what automation of systems we wish to achieve, there stays an important element, the employee - the individual. With the help of the employees the management of a supply chain changes itself within the decentralizing context of the Industry 4.0, so that they plan and manage individual processes, since not all of the operations or activities can be automated.

To meet, though, the Logistics 4.0 decentralisation requirements it is essential to provide for automation. The flow of products and information between the place of production and place of consumption is becoming smarter, more autonomous. The same can also be said about the flow of information between individual entities of the supply chain $[2,9,10]$.

With smart containers and wireless transport systems, the intra-logistics still supports smart production. Individual technical solutions, nevertheless, stay under development. (Hannover Messe)

This implies that the management of a supply chain in this interlinked and decentralised movement of industrial transformation as well as digital transformation of logistics is much more significant. Since intelligence and autonomy focus on digital platforms, consequently the decisions and tasks of the supply chain management are becoming essential. It is due to the fact that there is a better overview and more detailed monitoring of material as well as immaterial flows, which in turn strongly supports decision-making on the overall effectiveness of the SCM [7].

Based on the above it is possible to define other tasks of the smart logistics and SCM 4.0, specifically as follows [7,10-13]:

- Adding a proper level of autonomy and intelligence into the logistics, so that the company logistics as such is smarter, more effective, interconnected and flexible, and so that it meets the needs of an interconnected global economy,

- Defining a proper balance between the mutually controlled and autonomous systems and human planning, focusing on the activity and intelligence between an individual and machine, as well as recognition of environmental principles.

- Transforming the ways of work and management in line with implementation, basic principles and aspects of the Logistics 4.0, such as data analysis, information ecosystems, required skills for managing and correct decision-making in the changing environment of the decentralisation, fast decision-making, flexibility in the transition from centralized organization forms to the operational uncertainty planning and management. 
The whole principle of changes in Logistics 4.0 has aptly been demonstrated by the company UNITY Consulting and Innovation in a graphical illustration, Figure 1. Their assumption of further development of logistics even considers elimination of warehouses in the storage logistics $[2,6,14]$.

\section{UNITY Industry 4.0 Roadmap: Logistics}

\section{UNITY}

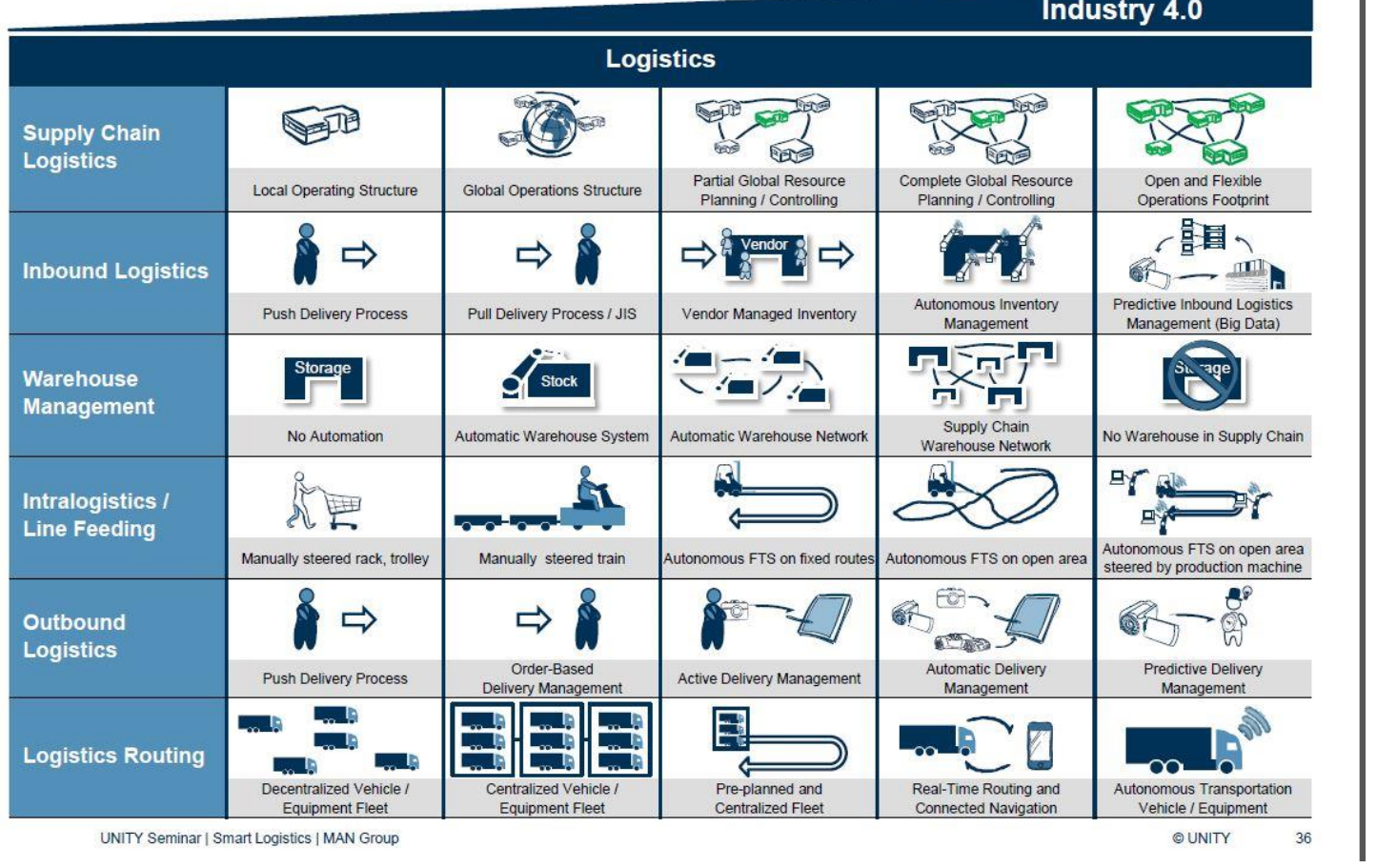

Fig. 1 Smart logistics and supply chain - the road ahead according to UNITY Consulting and Innovation. Source: [2]

\section{Conclusion}

Due to strong interconnection of innovations, internationalization and labour productivity, for the sake of a successful and reasonable implementation of Industry 4.0 it is very important to have a coordinated approach as well as a mutual linkage of industrial strategy, strategies in the area of information and communication technologies as well as the whole sector of services including thereby also the transport and shipping ones. The highly integrated economic system requires sophisticated strategies focused on the area of the whole global economy.

In conclusion we can state that the traditional schemes of the supply chain management are gradually being changed, some production companies analyse their possibilities of using the supply chain smart logistics as well as management 4.0, the other are forced to implement requirements of their business foreign partners faster. 


\section{References}

[1] Montero, S., Gozalvez, J. \& Sepulcre, M. (2017). Neighbor discovery for industrial wireless sensor networks with mobile nodes. Computer Communications, 111, 41-55. DOI: 10.1016/j.comcom.2017.07.004.

[2] Logistics 4.0 and smart supply chain management in Industry 4.0, Retrieved February 5, 2018, from https://www.i-scoop.eu/industry-4-0/supply-chain-management-scm-logistics/.

[3] Hirata, E. (2017). Contestability of Container Liner Shipping Market in Alliance Era. Asian Journal of Shipping and Logistics, 33(1), 27-32. DOI: 10.1016/j.ajs1.2017.03.004.

[4] Wan, J.F., Cai, H. \& Zhou, K.L. (2015). Industrie 4.0: Enabling Technologies. In IEEE, International Conference on Intelligent Computing and Internet of Things, 17-18 January 2015 (pp. 135-140). Harbin, China. ISBN 978-1-4799-7534-1.

[5] Dolinayova, A., Loch, M. \& Kanis, J. (2015). Modelling the influence of wagon technical parameters on variable costs in rail freight transport. Research in Transportation Economics, 54, 33-40. ISSN 0739-8859.

[6] Neradilova, H. \& Fedorko, G. (2017). Simulation of the supply of workplaces by the AGV in the digital factory. In 12th International Scientific Conference of Young Scientists on Sustainable, Modern and Safe Transport, Book Series: Procedia Engineering, 192, May-02 June 2017 (pp. 638-643). High Tatras, Slovakia. DOI: 10.1016/j.proeng.2017.06.110.

[7] Karakose, M. \& Yetis, H. (2017). A Cyberphysical System Based Mass-Customization Approach with Integration of Industry 4.0 and Smart City. Wireless Communications \& Mobile Computing, Article Number: UNSP 1058081. DOI: 10.1155/2017/1058081.

[8] Winebrake, J.J., Green, E.H., Corner, B., Li, C., Froman, S. \& Shelby, M. (2015). Fuel price elasticities in the US combination trucking sector. Transportation Research Part D - Transport and Environment, 38, 166-177. DOI: 10.1016/j.trd.2015.04.006.

[9] Diez, V., Arriola, A., Val, I. \& Velez, M. (2017). Validation of RF Communication Systems for Industry 4.0 through Channel Modeling and Emulation. In IEEE International Workshop of Electronics Control Measurement Signals and Their Application to Mechatronics, 24-26 May 2017. Donostia-San, Spain. ISSN 2379-5662.

[10] Behrends, V., Haunschild, M. \& Galonske, N. (2016). Smart telematics enabling efficient rail transport - development of the ViWaS research and development project. In 6th Transport Research Arena (TRA2016), Book Series: Transportation Research Procedia, 14, 18-21 April 2016 (pp. 4430-4439). Warsaw, Poland. DOI: 10.1016/j.trpro.2016.05.365. 
[11] Schlingensiepen, J., Nemtanu, F., Mehmood, R. \& McCluskey, L. (2016). Autonomic Transport Management Systems-Enabler for Smart Cities, Personalized Medicine, Participation and Industry Grid/Industry 4.0. Intelligent Transportation Systems - Problems and Perspectives, 32, 3-35. DOI: 10.1007/978-3-319-19150-8_1.

[12] Petro, V. (2017). Industry 4.0 and Information Communication Technologies. In IEEE 2nd International Conference on Information and Telecommunication Technologies and Radio Electronics (UkrMiCo2017), 11-15 September 2017. Odessa, Ukraine. ISBN 978-1-53861056-5.

[13] Paprocki, W. (2017). How Transport and Logistics Operators Can Implement the Solutions of "Industry 4.0". In Conference on Transport Development Challenges in the 21st century (TranSopot2016), Book Series: Springer Proceedings in Business and Economics, 23-25 May 2016 (pp. 185-196). Univ Gdansk, Fac Econ, Gdansk, Poland. DOI: 10.1007/978-3-31951427-7_16.

[14] Furmann, R., Furmannova, B. \& Wiecek, D. (2017). Interactive design of reconfigurable logistics systems. In 12th International Scientific Conference of Young Scientists on Sustainable, Modern and Safe Transport, Book Series: Procedia Engineering, 192, May-02 June 2017 (pp. 207-212). High Tatras, Slovakia. DOI: 10.1016/j.proeng.2017.06.036. 